\title{
AUTONOMIA NA VELHICE: CONCEPÇÕES DE IDOSOS PARTICIPANTES DE UM PROGRAMA DE AÇÃO SOCIAL
}

\author{
Sonia Mercedes Lenhard Bredemeier ${ }^{1}$ \\ Suzana Hübner Wolff² \\ Maria Regina Morales dos Santos ${ }^{3}$ \\ Anselmo Accurso ${ }^{4}$ \\ Aline Pereira Soares ${ }^{5}$ \\ Carolina Riegel ${ }^{6}$ \\ Daniela Moraes Martins ${ }^{7}$ \\ Orival Bonicoski8 \\ Silvana Bianchi9 \\ Soraya da Costa Noguez ${ }^{10}$
}

\footnotetext{
1 Assistente social, doutora em Serviço Social, professora jubilada da UNISINOS e coordenadora do GREG. E-mail: soniab@sinos.net

2 Graduada em Educação Física, doutora em Ciências do Movimento Humano, professora da UNISINOS, coordenadora do PRÓ-MAIOR e participante do GREG. E-mail: suzanaw@unisinos.br 3 Psicóloga, especialista em Psicossomática, membro do quadro técnico-funcional da UNISINOS e participante do GREG. E-mail: mrmorales@terra.com.br

4 Graduado em Educação Física, especialista em Educação Popular, professor da UNISINOS e participante do GREG. E-mail: anselmoaccurso@terra.com.br

5 Acadêmica do Curso de Psicologia e participante do GREG. E-mail: alinepsoares@hotmail.com

6 Acadêmica do Curso de Psicologia e participante do GREG. E-mail: carolmaister@gmail.com

7 Acadêmica de Enfermagem e participante do GREG. E-mail: daniramone@hotmail.com

8 Acadêmico de Enfermagem e participante do GREG. E-mail: oricoski1@yahoo.com.br

9 Acadêmica do Curso de Educação Física e participante do GREG. E-mail: silvanab@unisinos.br 10 Acadêmica do Curso de Educação Física e participante do GREG. E-mail: soraianoguez@hotmail. com
} 
resumo

Neste estudo o GREG ${ }^{11}$ propõe-se a identificar como os idosos do Programa PRÓ-MAIOR concebem a autonomia em suas vidas, considerando a contribuição da autonomia na qualidade de vida da pessoa idosa. Trata-se de uma pesquisa qualitativa exploratória, realizada através de entrevistas semiestruturadas, com oito idosos voluntários, que integram distintos grupos do Programa. Os dados analisados revelaram que autonomia relaciona-se com conhecimento, motivação, avaliação e capacidade decisória, que incluí a vontade de agir, ou seja, requer um comportamento proativo e que o exercício da autonomia relaciona-se com a saúde, a qualidade de vida e a independência financeira dos sujeitos de pesquisa.

palavras-chave

Envelhecimento Humano. Autonomia. Programa Social.

O estudo aqui apresentado está inserido no contexto do Programa de Ação Social: Pró-Maior da Universidade do Vale do Rio dos Sinos - UNISINOS, São Leopoldo, Rio Grande do Sul, onde, a partir da realidade experienciada, surgiu a necessidade de, por intermédio de um estudo científico, encontrar respostas a problemas identificados.

A partir de um estudo qualitativo exploratório, o grupo de pesquisadores buscou identificar se existe relação entre a autonomia humana e a capacidade individual e coletiva de tomada de decisão, ou se a concepção de autonomia está relacionada à dependência física e emocional dos idosos participantes do referido Programa.

A construção deste artigo apresenta a seguinte estrutura: uma revisão teórica sobre envelhecimento, autonomia e qualidade do envelhecer; a pesquisa de campo, junto aos idosos do Programa; e a análise e discussão de dados, esses devidamente identificados através de unidades de significado relacionadas ao referencial teórico.

O objetivo do grupo de pesquisadores, ao registrar essa reflexão da ação, é contribuir com os profissionais e acadêmicos envolvidos na questão

11 GREG - Grupo de Estudos Gerontológicos do Programa Maior Idade/PRÓ-MAIOR/Programa de Ação Social na Área do Envelhecimento Humano/Diretoria de Ação Social na Universidade do Vale do Rio dos Sinos - UNISINOS/RS. 
do envelhecimento humano, enfrentando os novos desafios que se revelam ao produzir conhecimento científico, a partir da realidade vivenciada.

\section{Referencial Teórico}

O envelhecimento da população idosa é crescente no Brasil, gerando a difícil responsabilidade individual e coletiva da promoção da melhoria das condições de vida daqueles que estão em processo de envelhecer. Camarano(2002) $)^{12}$ reforçam que em 2001 a população com 60 anos, ou mais, atingia a estimativa de 15 milhões $(8,6 \%)$ da população total, sendo projetado para 2020, um aumento desse número para $15 \%$ do total. A manutenção da autonomia e independência desse expressivo segmento é resultante de uma conquista social, pois segundo Kalache, Veras e Ramos (1987), ela está intimamente ligada à qualidade de vida, principalmente na velhice. Para os autores, é possível quantificar a qualidade de vida de um indivíduo através do grau de autonomia com que ele desempenha as funções do seu cotidiano, que o fazem independente dentro do seu contexto social, econômico e cultural. Paschoal (2002) destaca que autonomia e independência são dois indicadores de saúde e de qualidade de vida para a população idosa e que devem ser avaliados de forma abrangente e integradora.

Cordioli (2008, p. 814) afirma que alguns autores consideram a autonomia como centrada no indivíduo e outros, na interação dele com o meio. Para o referido autor, a autonomia pode ser definida como "a vontade individual exercida em um conjunto de oportunidades e restrições existentes".

Os idosos devem ter sua autonomia preservada e garantida. $\mathrm{O}$ fundamental é reconhecer que o ser velho não impede o indivíduo de tomar decisões e exercer plenamente sua vontade pessoal, considerando seus valores (GOLDIM, 2000).

Nesse sentido, Guattari (1987) propõe a distinção entre sujeito e sujeitado. O sujeito, ou o que tem vocação para sê-lo, se esforça para ter um controle sobre sua conduta, tenta elucidar seu objeto - ele enuncia alguma coisa. O sujeitado não se esforça em ter o controle sobre sua conduta, não se importa em ser ouvido, ou ouvir, evita operar o desapego à hierarquização de estruturas que lhe permitam se abrir além do grupo, se acomoda aos outros, recebe passivamente as determinações que vêm de fora, recusando, muitas vezes,

12 CAMARANO, Ana Amélia. Envelhecimento da população brasileira: uma contribuição demográfi-

ca. Texto para discussão, n. 167, IPEA, Rio de Janeiro, 2002. Apud BASTOS, CERQUEIRA, 2009. 
contato com a alteridade. Apoiados na distinção de Guattari (1987), ser velho não significa ser necessariamente um ser sujeitado, mas ser velho significa poder continuar sendo um sujeito, com autonomia.

Há uma dialética entre a dependência, propiciada pela necessidade de segurança, e a autonomia, propiciada pela busca de identidade e individuação. Tal relação se caracteriza por uma constante modificação e ajustamento. O equilíbrio entre a dependência e a autonomia muda com o desenvolvimento pessoal e os contextos ambientais. Ele muda, também, ao longo do curso da vida, de acordo com os valores, as expectativas e as exigências culturais e sociais (BALTHES; SILVERBERG) $1994^{13}$.

Na velhice, muitas vezes, a autonomia é desafiada pelas limitações físicas, sociais, psicológicas e econômicas impostas a um corpo mais vulnerável. A dependência física, confundida com dependência na tomada de decisão, dá origem a um paternalismo social de perigosas consequências, justificando $\mathrm{o}$ ato de se fazer tudo no lugar do idoso e negar a sua liberdade, autonomia e capacidade de escolha (NERI, 2007).

As limitações físicas de um corpo envelhecido podem trazer ao indivíduo uma sensação de perda da autonomia. Sendo assim, há um decréscimo na sua autoestima. Elas trazem, também, o sentimento de que "isto não é mais prá mim", pois envelhecer pode ser, antes de tudo, saber de suas limitações e redescobrir suas potencialidades. Para isso, é preciso de motivação, que muitos encontram na prática de atividades físicas em programas sociais, como é o caso do Programa PRÓ-MAIOR. Como afirmam Todaro e Jacob Filho (2009) ${ }^{14,15}$, o exercício físico beneficia tanto a saúde orgânica, quanto a psicológica, em todas as etapas da vida. Redescobrir suas potencialidades é buscar momentos onde os sentimentos possam se expressar, inclusive através do corpo.

Nesse sentido, a música pode se tornar uma grande aliada na prática de atividades físicas que busquem promover a manutenção da autonomia do sujeito que envelhece, visto que ela estimula sentimentos. A música mexe

13 BALTHES, Margareth M.; SILVERBERG, Susan B. The dynamics between dependency and autonoly; ilustratios across the life-span, 1994 In: D.L. Feartherman, R.M. Lerner e M. Perlmutter (Orgs.) Life-span development and behavior. Hillsdale: Lawrence Erlbaum Associates, v. 12, p. $42-90$ [s.d.]. Aoud NERI, 1995.

14 TODARO, Monica de Ávila; JACOB FILHO, Wilson. Dança: uma atividade física de corpo e alma. In DIOGO, Maria José D'Élboux; NERI, Anita Liberalesso; CACHIONI, Meire; (Orgs.,) Saúde e Qualidade de Vida na velhice. 3. ed. Campinas, SP: Alinea, p. 189-209, 2009 (Coleção velhice e sociedade). Apud DIOGO, NERI e CACHIONI, 2009.

15 O princípio que fundamenta a pesquisa é expresso nos seguintes termos pelos seus autores "exercitar-se faz bem tanto a saúde orgânica quanto psicológica em qualquer etapa de nossas vidas" (p. 201). 
com a alma. E ainda, a música associada à dança pode se tornar componente precioso na reconquista da autoconfiança e autocontrole. Todaro e Jacob Filho ${ }^{16}$ afirmam que "a dança movimenta o corpo para que a alma se expres$\mathrm{se}^{\prime \prime} \mathrm{O}$ ato de dançar propicia um sentimento de liberdade através do corpo, sem a preocupação de desempenho. Theodoro (1996, p. 157) complementa que "a dança sempre foi uma forma de todas as culturas manifestarem suas características próprias, sua maneira de perceber o corpo e a relação deste corpo com o mundo". Assim, ao perceber-se no mundo interagindo com seu corpo, através da dança, o indivíduo desbloqueia comportamentos corporais viciados, oportunizando esse mesmo conhecimento da realidade, só que pelo despertar do sentir, do criar, do comungar, forjando uma nova identidade, correspondendo às etapas da vida.

Essas idéias reforçam a valorização da inter-relação entre aspectos físicos e emocionais e autonomia, já destacados por Neri (1995). Outros autores também referem que a autonomia e a independência estão associadas, embora a independência não seja uma condição necessária para a manifestação da autonomia, já que ela está associada à autoconfiança e autocontrole.

Para Gruen (1986 apud Neri, 2006, p. 23), "o cerne do conceito de autonomia é a noção e o exercício do autogoverno, que inclui liberdade individual, privacidade, livre escolha, autorregulação e independência moral [...]".

Sé (2010) acrescenta à qualidade de vida, a liberdade de experenciar os eventos da vida com harmonia, com os próprios sentimentos e necessidades. Já a independência, para a autora, é a capacidade funcional, isto é, a capacidade de realizar as atividades do cotidiano sem ajuda, ou manejo instrumental. Sendo assim, déficits na capacidade funcional se refletem em dependência funcional, sendo que a dependência significa a incapacidade de funcionar sem ajuda, quer por dificuldades mentais, quer por dificuldades físicas.

Ter acesso às informações, ao conhecimento, pode fazer com que a pessoa idosa torne-se sujeito de sua vida. Assim ela poderá vir a buscar mais qualidade de vida. Entendida essa, nesse contexto, como: "a percepção do indivíduo de sua posição na vida no contexto da cultura e sistema de valores nos quais ele vive e em relação aos seus objetivos, expectativas, padrões e preocupações" (FLECK, 1999, p. 199).

Esses conceitos se entrelaçam de diferentes formas, tornando plenamente possível que uma pessoa seja dependente, mas sem perder sua autonomia.

16 TODARO, Monica de Ávila; JACOB FILHO, Wilson. Dança: uma atividade física de corpo e alma. In DIOGO, Maria José D'Élboux; NERI, Anita Liberalesso; CACHIONI, Meire; (Orgs.,) Saúde e Qualidade de Vida na velhice. 3. ed. Campinas, SP: Alinea, p. 189-209, 2009 (Coleção velhice e sociedade). Apud DIOGO, NERI e CACHIONI, 2009, p. 201. 
A autonomia, "é uma necessidade básica do ser humano e essencial ao bemestar subjetivo dos indivíduos" (SÉ, 2010, p. 1).

Associado à busca da autonomia, o curso da vida humana traz o envelhecimento como um processo natural, apresentando perdas em vários sentidos, tanto pessoais, como a perda da beleza tão almejada e exaltada pela sociedade, quanto perdas sociais, como a saída do mercado de trabalho e a aposentadoria. As perdas físicas, as biológicas e as emocionais, como o sentimento de solidão podem estar associadas a esta fase da vida. Diferente do que se percebe externamente, as funções cognitivas e psicológicas não envelhecem na mesma proporção, possibilitando o desenvolvimento de potencialidades e possibilidade de ganhos intelectuais, também nessa fase da vida (WOLFF, 2009b). A mesma autora, ainda afirma que, de uma forma geral, o inevitável enfraquecimento do corpo, com a velhice, remete a uma perda progressiva de independência e que, apenas entre as pessoas muito velhas, $\mathrm{o}$ envelhecimento psicológico causa mudanças de uma importância que pode ser percebida ou funcionalmente significativa.

Das transformações que marcam o envelhecimento contemporâneo, o surgimento da identidade de uma nova velhice, mais longa e com qualidade de vida, desafia a todos para o enfrentamento dessas questões, que envolvem o processo natural de envelhecimento e suas relações psicossociais (SILVA, 2009).

Ampliam-se estudos e pesquisas sobre o envelhecimento humano, visando a promoção de um envelhecimento saudável e a qualidade de vida dos que envelhecem. Porém, o prolongamento da vida nos vários segmentos da sociedade é desigual. A expectativa de vida entre aqueles mais privilegiados é bem maior do que nos segmentos mais carentes, com uma diferença de aproximadamente 20 a 30 anos (BASTOS; CERQUEIRA, 2009). Portanto, ao refletirmos sobre qualidade de vida e autonomia, cabe considerar esses dados.

Para Rodrigues e Terra (2006), a qualidade de vida na velhice é resultado da relação entre pessoas em mudança, vivendo em uma sociedade também em mudança e, especialmente, vista de uma forma multidimensional, respeitando as características biológicas, emocionais, psicológicas, econômicas, sociais, espirituais, ambientais, bem como, a relação do velho com a família e a sociedade, no percurso de sua vida.

Os mesmos autores destacam, ainda, os seguintes indicadores de bemestar na velhice: longevidade; saúde física e mental; desenvolvimento pessoal; satisfação e status social; autonomia e independência; renda; continuidade de papeis na família e na sociedade; relações interpessoais (formais e informais); 
e atividades laborativas (remuneráveis ou não), recreativas (socioculturais) e espirituais (transcendentais). Tais fatores concretizados através de "alimentação saudável; atividade física; atitude frente à vida além da capacidade de transformar o conceito de velhice-doença em velhice-ciclo vital" (p. 63). Concluem os referidos autores acima, que se o indivíduo se educar (ou reeducarse) aos bons hábitos, conseguirá obter uma boa qualidade de vida na velhice, descartando-se os fatores genéticos, os quais são, conforme estudiosos, equivalentes a 30\% dos aspectos que compõem a maneira de viver.

No entanto, não são somente as atitudes do indivíduo que favorecem o sucesso em sua velhice, pois ela depende também dos recursos comunitários disponibilizados pelas políticas públicas de saúde, educação, trabalho, cultura, lazer, seguridade social, dentre outras. Tal afirmativa se confirma na sentença: "Logo, o envelhecimento ativo não depende exclusivamente da pessoa, de ela ter estilos saudáveis de vida. Depende também das políticas públicas, econômicas, de investimento, por parte dos governos, tanto em nível municipal, como estadual e federal, [...]." (RODRIGUES; TERRA, 2006, p. 64).

Muitas pessoas atravessam seu curso de vida com déficits em saúde e educação, por razões econômicas e/ou sociais, e somente após seus 50 anos, ao adentrarem em programas e grupos de convivência relacionados à "terceira idade", conseguem modificar seus hábitos, praticando atividades esportivas, recreativas, sociais, culturais, artísticas e filantrópicas, modificando totalmente suas vidas, transformando o seu processo de envelhecimento em ativo e produtivo, isto é, em bem-sucedido (RODRIGUES; TERRA, 2006).

Tendo em vista essas considerações e o contexto no qual se insere este estudo, que é sobre o Programa Maior Idade/Pró-Maior da Universidade do Vale do Rio dos Sinos - UNISINOS, a pesquisa se apoia em dois suportes para seu desenvolvimento. O primeiro é o objetivo geral do próprio PróMaior, que se apresenta como um espaço de reflexão teórica nessa área, visto que o programa busca: "enfrentar as transformações biológicas, psicológicas, sociais e espirituais de pessoas (como protagonistas) com processo acelerado de envelhecimento (maiores de 50 anos) numa perspectiva de manutenção ou alcance do envelhecimento bem-sucedido, contribuindo para as políticas institucionais e públicas, na área do envelhecimento humano" (WOLFF, 2009a, p. 156).

Frente a esse desafio, o Grupo de Estudos Gerontológicos - GREG, como segundo objetivo, encontra nesta pesquisa a possibilidade de identificar como os idosos integrantes dos diversos grupos que compõem o Programa concebem a autonomia em suas vidas. A escolha do tema está relacionada 
à contribuição da autonomia na qualidade de vida da pessoa que envelhece e, de forma mais abrangente, à qualificação do desenvolvimento do Programa Pró-Maior da UNISINOS.

\section{Metodologia}

Este estudo se caracteriza por ser uma pesquisa qualitativa exploratória, que segundo Triviños (1987), possibilita explorar atitudes, comportamentos e opiniões do universo pesquisado. Na pesquisa qualitativa se decide intencionalmente o tamanho da amostra, levando em consideração os sujeitos que sejam essenciais para o esclarecimento do assunto pesquisado (TRIVIÑOS, 1987). A pesquisa exploratória, por sua vez, é aquela que envolve levantamentos bibliográficos e entrevistas com pessoas que tenham experiência prática com o problema pesquisado, possibilitando, ao pesquisador, um maior conhecimento sobre o assunto e uma visão geral do fato estudado (GIL, 1999).

Foram entrevistados oito participantes. Optou-se por esse número por tratar-se de uma pesquisa qualitativa, na qual, o que se busca são dados sobre um fenômeno em particular. A adesão dos mesmos foi voluntária. Tal adesão foi obtida anunciando-se a pesquisa nos grupos desenvolvidos pelo Programa Pró-Maior, vinculado à Diretoria de Ação Social da Universidade do Vale do Rio dos Sinos - UNISINOS, em atividade nas tardes em que havia disponibilidade dos pesquisadores. Solicitou-se que se manifestassem duas pessoas de cada grupo. Eram quatro oficinas que estavam sendo desenvolvidas. Já nesse momento, justificou-se o trabalho a ser feito, seus objetivos e quais os procedimentos que seriam adotados. Não foram estabelecidos critérios de exclusão, intencionalmente. Apresentou-se um grupo composto por um homem e sete mulheres, com a idade de 60 a 80 anos, aposentados, ou pensionistas, sendo que alguns ainda se envolviam com os afazeres domésticos. As entrevistas semiestruturadas foram realizadas em um ambiente reservado, para garantir a não identificação dos sujeitos e a confidencialidade das informações.

Quanto às entrevistas, realizadas individualmente, obteve-se o consentimento livre e esclarecido, em sua modalidade oral, por tratar-se de pessoas não vulneráveis e por não se abordar um assunto foro íntimo, qual seja, autonomia. Nesse caso, os sujeitos, apesar de idosos, são lúcidos, autônomos e independentes. Entende-se por consentimento "o termo que designa a manifestação livre e autônoma da vontade pessoal que, ligada à de outras pessoas, dá origem a um ato com validade jurídica ou ética. Existem dois 
tipos de consentimento: a) expresso, quando o consentimento se dá por via verbal, escrita ou por sinais inequívocos; b) tácito, se resulta de ação que revela a intenção do agente de consentir [...]" (PRUDENTE, 2000, p. 55). Por outro lado, para obter o consentimento, cabe observar que sejam dados os esclarecimentos, garantindo informações sobre o que segue, conforme a Res. 196/96. :" a) a justificativa, os objetivos e os procedimentos que serão utilizados da pesquisa; [...] e) a garantia de esclarecimento, antes e durante o curso da pesquisa, sobre a metodologia, [...]; f) a liberdade do sujeito se recusar a participar ou retirar seu consentimento, em qualquer fase da pesquisa, sem penalização alguma e sem prejuízo ao seu cuidado; g) garantia do sigilo que assegure a privacidade dos sujeitos quanto aos dados confidenciais envolvidos na pesquisa; [...]" (BRASIL, 2006, IV.1. p. 92-93). Ainda, no que tange aos sujeitos, não são os mesmos considerados vulneráveis, com base na Res. 196/96, que considera vulnerabilidade o estado de pessoas, ou grupos, que por quaisquer razões, ou motivos, tenham reduzida sua capacidade de autodeterminação reduzida, sobretudo no que se refere ao consentimento livre e esclarecido (BRASIL, 2006, II. 15). Diante disso, entende-se que o perfil dos participantes e o contexto da investigação, na visão dos pesquisadores, são coerentes com a adoção do termo de consentimento "expresso" apenas. Como ainda pode ser verificado, de acordo com os esclarecimentos anteriores, os preceitos éticos foram observados pela equipe de pesquisa, que teve zelo pelos seus sujeitos e pelas implicações do estudo.

As entrevistas semiestruturadas permitiram que os sujeitos de pesquisa expressassem suas opiniões e seus sentimentos a respeito do tema trabalhado. As entrevistas foram gravadas com a concordância dos sujeitos e, posteriormente, transcritas sem alterações dos termos utilizados, sendo preservada a identidade dos sujeitos.

As questões apresentadas aos pesquisados foram:

-"Fale sobre a noção de autonomia e em que contexto ela se estabelece".

-"Fale sobre quais as principais características de uma pessoa com autonomia".

-"Se desejar, faça outro comentário sobre autonomia".

As hipóteses embasadoras deste estudo foram consideradas a partir das possíveis respostas às questões de pesquisa estabelecidas. Busca-se na pesquisa comprová-las, ou não. São elas:

* Autonomia está relacionada com a capacidade decisória.

* Autonomia não está relacionada com a capacidade decisória.

* A dependência do idoso está relacionada com a sua concepção de autonomia. 
Frente aos dados coletados e com o aporte da técnica de análise de conteúdo (GOMES apud MINAYO, 2004), constata-se que nas concepções de autonomia presentes entre os idosos participantes dos grupos do Programa Pró-Maior é recorrente a ideia de que autonomia está relacionada, principalmente, à independência física. Os sujeitos associam também, autonomia à capacidade de decisão, à não dependência de outrem no seu cotidiano, como ainda, à responsabilidade, à vontade de decidir e à autoconfiança.

$\mathrm{Na}$ análise das falas dos entrevistados, destacaram-se aquelas que se referem, diretamente, aos aspectos em questão nas hipóteses, em função dos limites deste registro.

\section{A - Quanto à autonomia relacionada à independência física:}

Observa-se, nas percepções dos sujeitos de pesquisa, a presença da relação da autonomia com a independência física, conforme relato a seguir:

"Eu tenho autonomia, porque eu posso ainda fazer as minhas coisas, viu? Eu posso ir ao banco, eu posso ir ao mercado, eu posso me decidir o que eu vou comprar" (afazeres domésticos, 79 anos).

Nesse sentido, Neri (2007) afirma que a capacidade funcional, em sua expressão máxima, significa poder sobreviver sem ajuda para realizar as atividades instrumentais de vida diária e de autocuidado. Para Kalache, Veras e Ramos (1987), a capacidade funcional está ligada intimamente à manutenção da autonomia e esta, à qualidade de vida, fato esse, claramente identificado na fala da entrevistada acima mencionada. Isso pode justificar o conceito de capacidade funcional, que é também conhecido como desempenho prático.

\section{B - Quanto à autonomia relacionada à capacidade de decisão}

Caracteriza-se, nas falas a seguir, a presença do trinômio: informação, avaliação e decisão, como determinantes da autonomia, conforme apresentam os relatos:

"Muitas e muitas vezes eu consulto as minhas filhas, a minha família, tenho as duas filhas casadas; porque eu gosto de ouvir o que as outras pessoas dizem, porque daí abrem os meus horizontes! E daí eu posso fazer uma avaliação geral, e daí eu decido o que eu quero" (aposentada, 71 anos).

"Eu pego o trem, eu vou para Porto Alegre, eu faço! Isso eu sinto que seja autonomia. Para decidir alguma coisa eu posso ouvir o que os outros dizem na minha casa, mas a autonomia é minha, porque eu decido no final" (afazeres domésticos, 75 anos). 
Aqui se percebe a ideia presente no conceito de qualidade de vida em Fleck (1999), anteriormente citada.

Para Goldim (2000), a autonomia incorpora duas conviç̧ões éticas: os indivíduos devem ser tratados como agentes autônomos; as pessoas com autonomia diminuída devem ser protegidas. Para tomada de decisão, o idoso deve envolver-se com o assunto, compreender ou avaliar as alternativas e comunicar sua decisão e, assim, desenvolver a competência para pensar e deliberar.

Novamente transparece aqui a capacidade de decisão aliada ao acesso à informação.

\section{C - Quanto à autonomia relacionada à não dependência de outrem no seu cotidiano}

"A pessoa que se dirigi por si mesma, não é? Não precisar ficar sempre perguntando ou pedindo para as pessoas fazerem as coisas para ela" (afazeres domésticos, 69 anos).

"É pessoas que se torna apta a resolver seus problemas" (aposentado, 73 anos).

"Eu ainda tenho disponibilidade. Tenho vontade de fazer as coisas. É uma coisa muito importante na vida da gente. Acho que o fato da gente ter autonomia para fazer as certas coisas faz muito bem para a vida da gente, ainda mais na nossa idade" (afazeres domésticos, 65 anos).

Frente aos depoimentos acima, relacionados à autonomia, Cordioli (2008) afirma que alguns autores a consideram como sendo uma ação centrada no indivíduo. Já, outros, na interação desse indivíduo com o meio. Para o referido autor, a autonomia pode ser definida como "a vontade individual exercida em um conjunto de oportunidades e restrições existentes" (p. 814).

\section{D - Quanto à autonomia relacionada com responsabilidade}

Os seguintes depoimentos confirmam essa percepção nas falas dos sujeitos pesquisados: “O sentido da palavra para mim é ter responsabilidade naquilo que tu faz, mesmo estando certo ou errado." (aposentada, 68 anos)

"É a pessoa que faz um trabalho autônomo. Ele é responsável por aquilo que ele faz" (aposentado, 76 anos).

Para esses sujeitos, a possibilidade da tomada de decisão está intrinsecamente relacionada ao domínio da situação, à experiência acumulada e ao conhecimento. Nesse sentido, observa-se que a autonomia implica em responsabilidade, assumindo erros e acertos na tomada de decisão. 
A percepção de autonomia, de acordo com os integrantes do Pró-Maior entrevistados, encerra em si o desejo, a vontade de agir, a liberdade individual, ou seja, requer um comportamento pró-ativo. Para eles, é fundamental o indivíduo tomar suas decisões e sua vontade pessoal.

Ainda, o fato de exercer autonomia relaciona-se com saúde e, nesse sentido, com a qualidade de vida, a qual depende de uma relação entre as circunstâncias da vida do indivíduo e um padrão por ele estabelecido. Perpassa também, nessas concepções, a independência financeira dos sujeitos pesquisados.

Com base no anteriormente exposto, pode-se afirmar que, nesse contexto, para exercer autonomia são indispensáveis pré-condições, como informação, avaliação, comunicação, decisão e capacidade para gerir sua própria vida.

As hipóteses deste estudo, sendo a primeira, a relação entre autonomia e capacidade decisória, bem como a terceira, de que a dependência do idoso se relaciona com a sua concepção de autonomia, são comprovadas. Já a segunda hipótese, contrária à primeira, não se confirma.

Levando em conta essas constatações, sugere-se, a partir deste estudo, a manutenção e ampliação de oportunidades de ação/intervenção dos idosos participantes do Programa, considerando os limites operacionais e institucionais, na perspectiva de protagonizarem cada vez mais, o processo individual e coletivo de manutenção e ampliação da autonomia percebida.

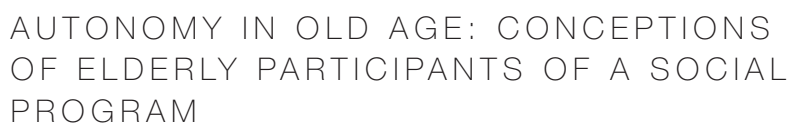

In this study GREG proposes to identify how the elderly participants of the Program PRÓ-MAIOR conceive autonomy in their lives, considering the contribution of autonomy in the elderly quality of life. This is an exploratory qualitative research, conducted through semistructured interviews with eight elderly volunteers that comprise distinct groups of the Program. The analysis showed that autonomy is related to knowledge, motivation, evaluation and decision capacity, 
which includes the will to act, that means, it requires a proactive behavior and that the exercise of autonomy is related to the health, the quality of life and the financial independence of the research subjects.

keywords

Human Aging. Autonomy. Social Program.

referências

BASTOS, Silvia; CERQUEIRA, Monique Borba. Qualidade de vida e as múltiplas dimensões do envelhecimento. Ilhéus, Memorialidades, n. 11, jan./jun. 2009, p. 37-61.

BEMVENUTI, Vera Lúcia (Org.). Cademos de Extensão V. São Leopoldo, UNISINOS, 2009.

BRASIL. Ministério da Saúde, Resolução n 196 de 10 de outubro de 1996. Conselho Nacional de Saúde. Comissão Nacional de Ética em Pesquisa. Manual operacional para comitês de ética em pesquisa. 4. ed. rev. atual. Brasília, 2006.

CAMARANO, Ana Amélia. Envelhecimento da população brasileira: uma contribuição demográfica. Texto para discussão, n. 167, IPEA, Rio de Janeiro, 2002.

CORDIOLI, Aristides Volpato (Org.). Psicoterapias: abordagens atuais. 3. ed. Porto Alegre: Artmed, 2008.

DIOGO, Maria José D'Élboux; NERI, Anita Liberalesso; CACHIONI, Meire; (Orgs.). Saú de e Qualidade de Vida na veltice. 3. ed. Campinas, SP: Alinea, 2009 (Coleção velhice e sociedade).

FLECK, Marcelo P. A. (Coord.) et al. Whoqol-100. OMS - Avaliação da qualidade de vida. Versão em português. Revista de Saúde Pública, São Paulo, v. 33, n. 2, abr. 1999. Disponível em: <http://www.ufrgs.br/psiq/whogol.pdf>. Acesso em: 01 de jul. 2010.

GlL, Antonio Carlos. Métodos e técnicas de pesquisa social. 5. ed. São Paulo: Atlas, 1999 .

GOLDIM, José Roberto. Autonomia, Tomada de Decisão e Envelhecimento. Disponível em: <http://umw.bioetica.urfrgs.br/textos.htm>. Acesso em: 1 de jul. 2010.

GOMES, Romeu. A análise dos dados em pesquisa qualitativa. In: MINAYO, Maria C. (Org). Pesquisa social: Teoria, método e criatividade. 22. ed. Petrópolis: Vozes, 2004.

GUATTARI, Felix. Revolução Molecular: pulsações políticas do desejo. São Paulo: Editora Brasiliense, 1987.

GUIA PARA A ELABORAÇÃO DE TRABALHOS ACADÊMICOS (artigo de periódico, dissertação, projeto, trabalho de conclusão de curso e tese). São Leopoldo, jul. 2009. Disponível em: <http://mww.unisinos.br/biblioteca/images/stories/downloads/guia_academico_trabalhos_cientificos_2010.pdf>. Acesso em: 22 de mar. 2010.

KALACHE, Alexandre; VERAS, Renato P.; RAMOS Luiz Roberto. O envelhecimento da população mundial: um desafio novo. Disponível em: <http://www.scielosp.org/ scielo.php?pid=S0034-89101987000300005\&scri... >. Acesso em: 11 de nov. 2010. 
In:___. Envelhecimento Cronológico versus envelhecimento funcional: o conceito de autonomia. Revista de Saúde Pública, São Paulo, v. 21/03, 1987

MINAYO, Maria Cecilia de Souza (Org.). et al. Pesquisa Social: Teoria, Método e Criatividade. Petrópolis: Vozes, 2004.

NERI, Anita Liberalesso (Org.). Psicologia do envelhecimento. Campinas, SP: Papirus, 1995.

Palavras-Chave em Gerontologia. Campinas: Alínea, 2006.

Qualidade de Vida na velhice: enfoque multidisciplinar. Campinas: Alínea, 2007.

Saúde e Qualidade de Vida na Velhice. 2. ed. rev. Campinas, SP: Alínea, 2006 (Coleção velhice e sociedade).

PASCHOAL, Sérgio Márcio. Pacheco. In: NEITO, Matheus Papaléo. Gerontologia: a veIhice e o envelhecimento em visão globalizada. São Paulo: Atheneu, p. 313-323, 2002.

NEITO, Matheus Papaléo. Gerontologia: a velhice e o envelhecimento em visão globalizada. São Paulo: Atheneu, p. 313-323, 2002.

PRUDENTE, Mauro Godoy. Bioética: conceitos fundamentais. Porto Alegre: Ed. Do Autor, 2000.

RODRIGUES, Nara da Costa; TERRA, Newton Luis. Gerontologia social para leigos. Porto Alegre: EDIPUCRS, 2006.

SÉ, Elisandra. V. G. Autonomia, dependência e independência durante a vida. Mente na terceira idade e gerontologia. Vya Estelar. Disponível em: <http://www2.uol.com.br/ vyaestelar/autonomia_funcional_velhice.htm>. Acesso em: 1 de jul. 2010.

SILVA, Luna Rodrigues Freitas. Autonomia, imperativo à atividade e "máscara da idade": prerrogativas do envelhecimento contemporâneo? Revista Psicologia \& Sociedade, v. 21 , n. 1, 2009. Disponível em: <www.6.ufrgs. br/seerpsicsoc/ojs/viewarticle.php?id=541>. Acesso em: 1 de jul. 2010.

THEODORO, Helena. Mulheres Negras: Mito e espiritualidade. Rio de Janeiro: Pallas, 1996.

TRIVIÑOS, Augusto Nivaldo Silva. introdução à Pesquisa em Ciências Sociais: a pesquisa qualitativa em educação. São Paulo: Ática, 1987.

WOLFF, Suzana H. Ação social na área do envelhecimento humano: retrato de um contexto. In: BEMVENUTI, Vera Lúcia (Org.). Cademos de Extensão V. São Leopoldo, UNISINOS, 2009a.

Envelhecimento bem-sucedido e políticas públicas In: Vivendo e EnveThecendo: recortes de práticas sociais nos Núcleos de Vida Saudável. São Leopoldo: UNISINOS, p. 15-30, 2009b.

Recebido: 23/12/2010

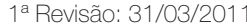

2a Revisão: 20/07/2011

$3^{a}$ Revisão: 03/10/2011

$4^{a}$ Revisão: 28/10/2011

5a Revisão: 06/12/2011

Aceite Final: 06/12/2011 